\title{
Essential Work of Fracture and Size Effect in Copper/Glass-Reinforced Epoxy Laminate Composites Used as MEMS Devices
}

\author{
Mohamed K. Hassan ${ }^{1,2}$, Mohammed Y. Abdellah, ${ }^{2,3, *}$, Tareq S. ElAbiadi ${ }^{1}$, Ahmed F. Mohamed ${ }^{2,4}$, S. Azam $^{2}$, \\ W.W. Marzouk ${ }^{1}$ \\ ${ }^{1}$ Production Engineering and Design Department, Faculty of Engineering, Minia University, Minia, Egypt \\ ${ }^{2}$ Mechanical Engineering Department, Collage of Engineering and Islamic Architecture, Umm Al-Qura University Makkah, KSA \\ ${ }^{3}$ Mechanical Engineering Department, Faculty of Engineering, South Valley University, Qena \\ ${ }^{4}$ Mechanical Engineering Department, Faculty of Engineering, Sohage University, Egypt \\ *Corresponding author: mohammed yahya42@yahoo.com
}

\begin{abstract}
Microelectromechanical systems (MEMS) are made of components in the range of 1 to 100 micrometers. These systems have a large application in electrical and electronic devices. The manufacturing of MEMS categorized under semiconductor device branch fabrication. The performance of such precision material very strongly depended on the mechanical and fracture properties of the composite material they get fabricated from. A MEMS thin strips are manufactured by bonding a thin copper film on a substrate of glass-reinforced laminated fabric with an epoxy resin binder. Generally, the tested samples are glass fiber laminates with a $1.5 \mathrm{~mm}$ thickness having 35-micron copper layer. Two sets of samples were cut; first ones are in the form of a flat specimen with a small hole at the center for size effect tests whereas, the second ones are double edge notch (DENT) specimens for essential work of fracture tests. The fracture toughness of such material is measured using essential work of fracture tests. These types of material are considered a quasi-brittle material which mainly anisotropic material, therefore, the size effect is tested over this material. The results showed that the essential work of fracture for this MEMS material is measured as $72.883 \mathrm{~kJ} / \mathrm{m}^{2}$ and is subject to size effect which make a reduction in nominal strength namely $15 \%$.
\end{abstract}

Keywords: MEMs, fracture toughness, size effect, essential work of fracture

Cite This Article: Mohamed K. Hassan, Mohammed Y. Abdellah, Tareq S. ElAbiadi, Ahmed F. Mohamed, S. Azam, and W.W. Marzouk, "Essential Work of Fracture and Size Effect in Copper/Glass-Reinforced Epoxy Laminate Composites Used as MEMS Devices." American Journal of Mechanical Engineering, vol. 5, no. 5 (2017): 234-238. doi: 10.12691/ajme-5-5-7.

\section{Introduction}

Composite material nowadays has a competitive role in electronic [1] industry. Microelectromechanical systems (MEMS) have largely influenced by mechanical and thermal properties in case of reliability and performance [2]. A lot of studies had been conducted to modeling, design, selecting and production process of (MEMS), while studies in the characteristic of its reliability and durability in mechanical an fracture behaviors under loads are not fully understood [3].

Hassan et al. [1] investigated the fatigue behaviors of thin copper film bonded to the steel substrate using two types of bonding technique; one of them is epoxy resin the other is the diffusion bonding. They concluded that the fatigue performance enhanced with the diffusion technique.

Ballarini et al. [3] studied the fracture $\mathrm{J}_{\mathrm{c}}$ for polysilicon specimen machined in a similar and identical way for MEMS. They reported that there is a factor 4 larger than release energy of a single crystal.
Espinosa et al. [4] studies fracture toughness of MEMS material fracture toughness and thin film used in these fields. They measured fracture toughness behaviors of the ultra-nanocrystalline diamond. They established that initiation fracture for bland crack larger than that of a sharp crack tip, they give a correction factor value for the material using the model of Drory et al. [5].

Kahn et al. [6] measure the fracture toughness of polysilicon MEMS devices using finite element analysis for experimental results. These experimental results were obtained using an especial sharpened mechanism to ensure accurate crack initiation and propagation perdition. The fracture toughness of MEMs was measured in, finite radius notch, which is not the actual mems case, for the study of Sharpe, et al [7] and Tsuchiya et al. [8]. They fractured their specimen using a piezoelectric load cell.

Abdellah [9] used essential work of fracture (EWF) to measure thin aluminum strip. A simple numerical model using finite element is extracted to predict the parameters of EWF. The experimental results were in good agreement with the proposed model, but the specimen was on the scale of a millimeter. Copper thin film bonded to a steel plate substrate is quasi-brittle material supposed 
commonly subjected to size effect as reported in many other works [10-19].

Hassan et al [20] used cohesive zone model to predict size effect of glass fiber reinforced epoxy. The results of quasi-brittle material predicted well with the produced model.

Mohammed et al. [21] investigated size effect of quasibrittle material using both analytical model and experimental test. They established good prediction for size effect and give reasons for these effects and find some resolved the problem of size effect.

\section{Goal of the Present Study}

The present work has two main goals, they are as follows;

1-Evaluation of static surface release energy using essential work of fracture method

2-Establish size effect over copper thin film bonded to composite structure used in MEMs fabrication

The paper methodology is as follows; in the first section, material and experimental methods are outlined, second section deals with results and discussion and the conclusions are done in the final section.

\section{Material and Testing}

The Composite structure is made of a glass fiber reinforced epoxy laminate of $1.5 \mathrm{~mm}$ thickness. 24 layers of woven glass fiber are used as a substrate while a thin film of copper of nearly $35 \mathrm{micron}$ is bonded to the base material using epoxy resin film as shown in Figure 1. The chemical composition and mechanical properties of the copper and epoxy are listed in Table 1 and Table 2. The DENT specimen with $40 \mathrm{~mm}$ width according to [22,23] is tested as shown in Figure 2, to complete failure at a universal testing machine (model machine WDW-100) of maximum capacity $20 \mathrm{kN}$. The crack is cut, using Proto Mat S103 PCB milling machine from LPKF, with $1 \mathrm{~mm}$ diameter end mill cutter. The DENT specimen is selected to avoid buckling, this because of the specimen symmetry (see Figure 2). The sharp load drop is affected by the specimen buckling [24,25,26,27]. The cross-head speed of the test is selected to be of $2 \mathrm{~mm} / \mathrm{min}$ according to [28]. Five specimens are tested for each various ligament lengths of $(2,4,8,12,16,20,24$ and 28) at room temperature [29]. The mechanical energies $W_{y}$ and $W_{p p}$ are calculated from the integration of the resulting load-displacement curves according to the following:

$$
\begin{gathered}
W_{y}=\int_{0}^{\delta_{0}} p d \delta \\
W_{p p}=\int_{\delta_{0}}^{\delta} p d \delta
\end{gathered}
$$

where $\delta_{0}, \delta$ are displacement at $0.02 \%$ offset and at failure repetitively and $p$ is the applied load.

$$
W_{f}=W_{e}+W_{p}
$$

The obtained total energy $W_{f}$ (measured using Eqn. 3) is plotted corresponding ligament lengths L (see Eqn. 4). The displacement at fracture $\left(\delta_{b}\right)$ can be plotted against ligament length $\mathrm{L}$ according to [22].

$$
w_{f}=\frac{W_{f}}{L t}=w_{e}+\beta w_{p} L
$$

A MEMS plate is of $1.5 \mathrm{~mm}$ thickness, $150 \mathrm{~mm}$ length was cut into specimens of five different hole diameters, $\mathrm{d}=0.5 \mathrm{~mm}, 1 \mathrm{~mm}, 2 \mathrm{~mm}, 3 \mathrm{~mm}, 4$ and $5 \mathrm{~mm}$ and with a

\begin{tabular}{|c|c|c|c|c|c|c|c|}
\hline phase & Al & $\mathbf{N i}$ & Sn & $\mathbf{P b}$ & $\mathbf{F e}$ & $\mathbf{Z n}$ & Mn \\
\hline Copper film & $0.0005>$ & $0.0005>$ & $0.0005>$ & $0.0005>$ & $0.0005>$ & $0.0005>$ & $0.0005>$ \\
\hline Glass fiber & \multicolumn{7}{|c|}{ E-glass -roving-pl=2200 gm $/ \mathrm{km}$} \\
\hline Epoxy & \multicolumn{7}{|c|}{ Resin-Kemapoxy(150RGL) } \\
\hline
\end{tabular}
width to diameter ratio (w/d) equal 6 [20,30]. The open hole tension test matrix is listed in Table 3 .

\begin{tabular}{|c|c|c|}
\hline phase & Young modulus, E (GPa) & Thermal of linear expansion, $\alpha / K$ \\
\hline Copper film & 123 & $1.68 \times 10^{-5}$ \\
\hline Glass fiber & 24(Length Wise), 21 (Cross Wise) & $4.0 \times 10^{-5}$ \\
\hline Epoxy & $1.2-4.5$ & 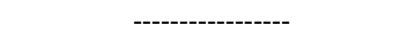 \\
\hline
\end{tabular}

Table 1. Chemical composition of copper film and base glass fiber [1]

Table 2. Mechanical properties [1]

Table 3. Electrical properties

\begin{tabular}{ccc}
\hline phase & Electrical Resistivity, $\boldsymbol{\rho}(\mathbf{\Omega} \bullet \mathbf{m})$ & Dielectric Strength, V/mil \\
\hline Copper film & $1.68 \times 10^{-8}[22]$ & ------- \\
\hline Glass fiber & $10[23]$ & $>762[23]$ \\
\hline Epoxy & $>1 \times 10^{5}[24]$ & $500[24]$ \\
\hline
\end{tabular}


Table 4. Experimental matrix program

\begin{tabular}{cccc}
\hline Diameter & Width & Ratio $\mathbf{w} / \mathbf{d}$ & Number of specimens used \\
\hline $\mathbf{d}_{\mathbf{1}=\mathbf{0 . 5}}$ & 3 & 6 & 5 \\
\hline $\mathbf{d}_{\mathbf{1}}=\mathbf{1}$ & 6 & 6 & 5 \\
\hline $\mathbf{d}_{\mathbf{2}}=\mathbf{2}$ & 12 & 6 & 5 \\
\hline $\mathbf{d}_{\mathbf{3}}=\mathbf{3}$ & 18 & 6 & 5 \\
\hline $\mathbf{d}_{\mathbf{4}}=\mathbf{4}$ & 24 & 6 & 5 \\
\hline $\mathbf{d}_{\mathbf{5}=\mathbf{5}}$ & 30 & 6 & 5 \\
\hline $\mathbf{d}_{\mathbf{5}}=\mathbf{6}$ & 36 & 6 & 5 \\
\hline $\mathbf{d}_{\mathbf{5}}=\mathbf{7}$ & 42 & 6 & 5 \\
\hline
\end{tabular}

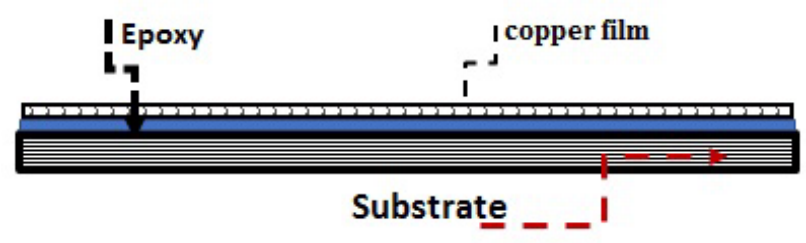

Figure 1. Schematic diagram of MEMS specimen

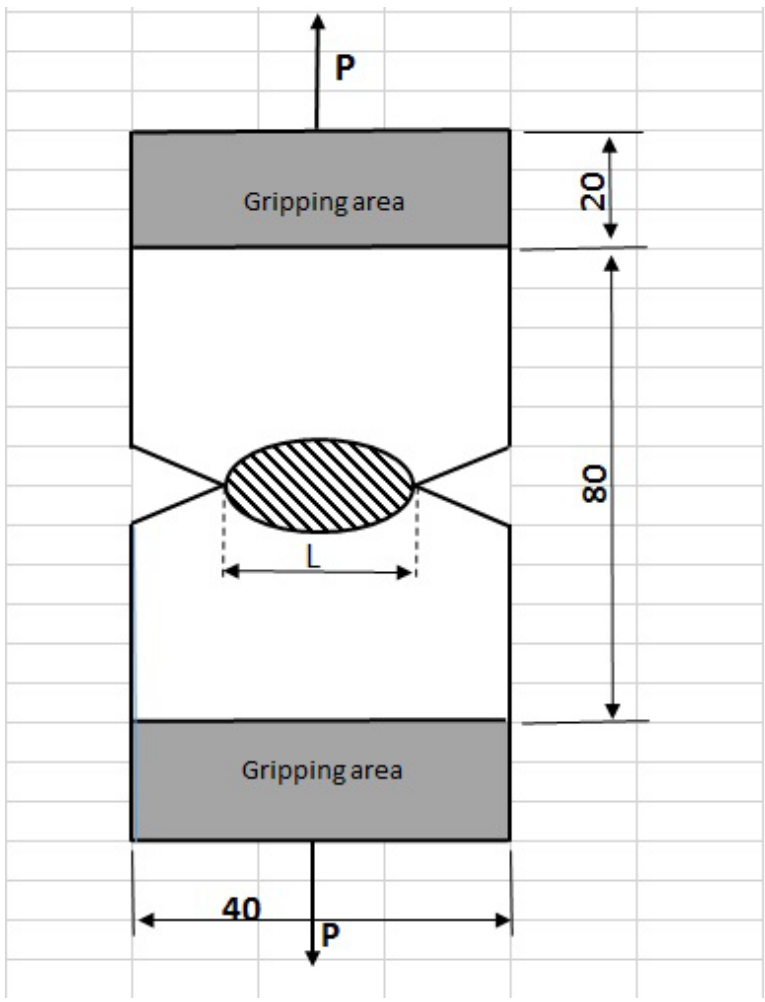

Figure 2. schematic drawing of double edge notched test (DENT) specimen [9]

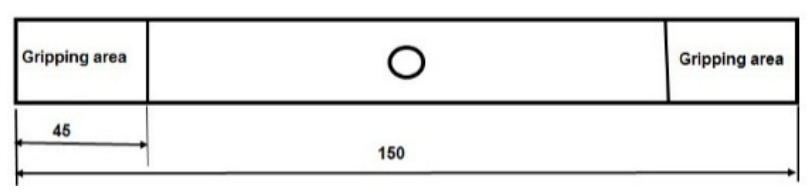

Figure 3. Open hole specimen for size effect test

\section{Results and Discussion}

Figure 4 show load-displacement diagram for each specimen ligament, it is well knowing that area under load-displacement relation give total work done in fracture and tearing of the deformed material. The total work done $W_{\mathrm{f}}$ is plotted for each corresponding ligament length according to that of equation 4 . This plot is shown in Figure 5, which gives two main parts of the essential work of fracture; the essential work We which can be called fracture release energy and non-essential work which is an indication of plastic work done dissipated through specimen fracture $\left(\beta w_{p} L\right)$. The essential work of fracture is the intersection point between the linear line of fitting with the vertical (Y) axis and is measured nearly as $72.883 \mathrm{~kJ} / \mathrm{m}^{2}$. The failure mode for all tested specimen is net tension with orthogonal failure plan as seen in Figure 6. There was fiber tension and breakage for all specimen this is attributed to good adhesive of the used composite laminates. No delamination was observed through laminate structure or through copper thin film composite laminates interface, this is due to good dependability between the material. The release energy or the essential work of fracture has an increasing value compered to glass fiber reinforced epoxy only nearly in rang of 20-30 [31], this is really attributed to the exit of copper thin film which give some isotropy and make the hybrid composite more effective and can withstand the electronic application with subjected to high frequencies of electricity. The hybrid composite plate as quasi-brittle material is subject to the size effect. Figure 7 shows size effect over all the tested matrix specimens. It is observed that strength decreases with specimen size increase with nearly $15 \%$ by increasing specimen size from $0.5 \mathrm{~mm}$ diameter and $3 \mathrm{~mm}$ width to $7 \mathrm{~mm}$ diameter and $42 \mathrm{~mm}$ width specimens. This mainly returns to that the thin copper film glass fiber composite laminates are anisotropic material and with the size increase flaws increase inside the specimen and stress concentration factor increase around crack tip. However, the percent of decrease is less than that of glass fiber composite laminates only as the thin copper film give some isotropy to the global composites. The size effect nearly stable with the increasing specimen size at $4 \mathrm{~mm}$ diameter to $7 \mathrm{~mm}$ diameter the percentage very small nearly $3 \%$. As clearly observed in Figure 8. Modes of failure for all tested specimen is neat tension around the holes with right angle to it (see Figure 9). No shear band observed, also no serve delamination was observed just at the crack plan with some fiber pull out and breakage. 


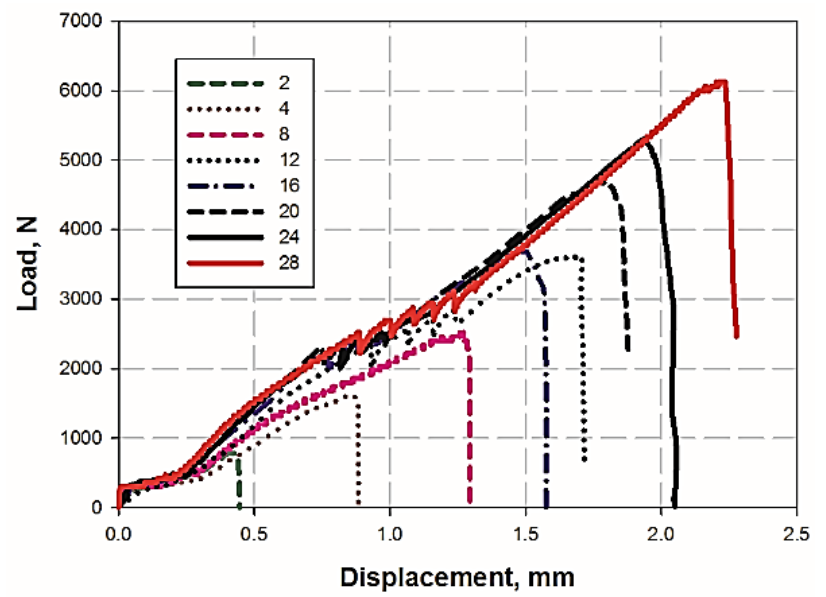

Figure 4. load-displacement relation function with various ligament length

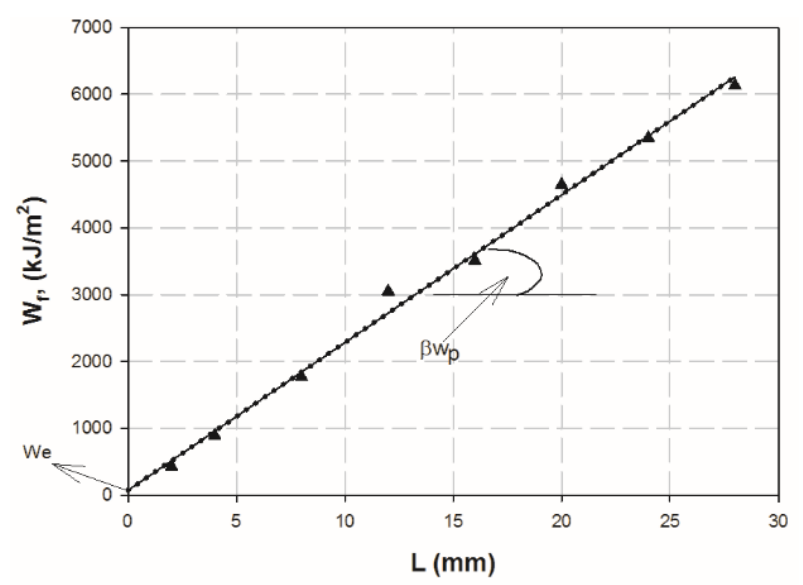

Figure 5. EWF fitting for total work verse ligament length

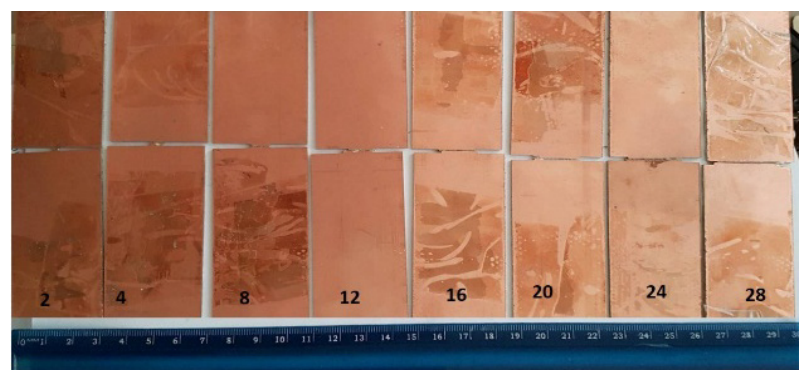

Figure 6. Modes of failure in DENT

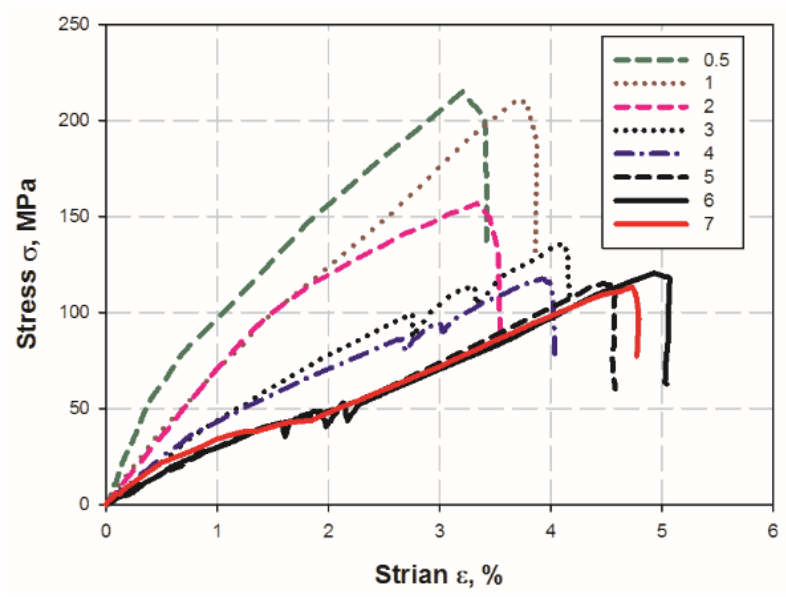

Figure 7. Stress-strain diagram for open hole composite structure

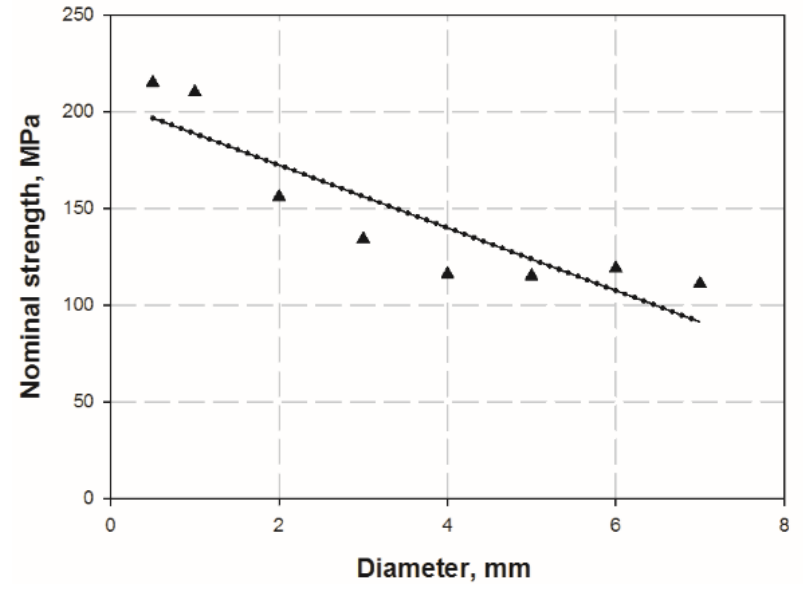

Figure 8. Size effect curve in composite structure

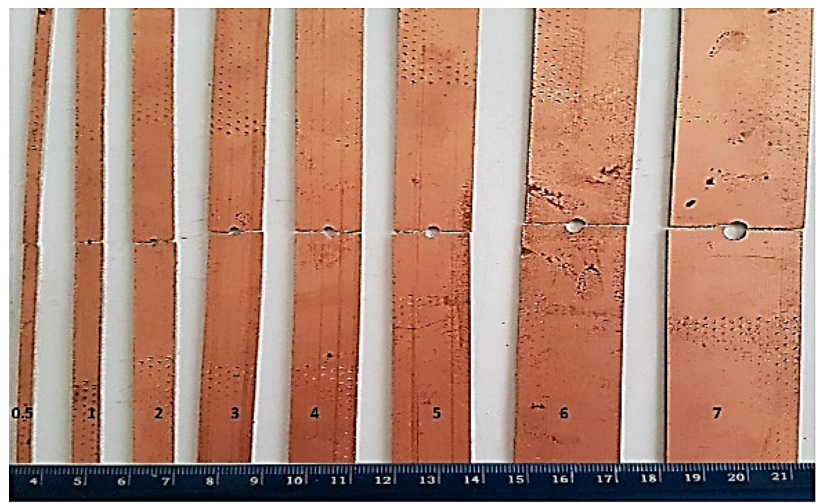

Figure 9. Modes of failure in open hole specimen

\section{Conclusion}

Thin copper layer bonded on glass fiber epoxy composites are considered as a hybrid composite material which is widely used in MEMS device industry. Fracture energy has great importance in such material when using this important parameter in the modeling and the prediction of the strength of these materials based on cohesive laws or even to characterize the mechanical properties. The release energy $\mathrm{G}_{\mathrm{IC}}$ for mode- 1 is measured as $72.883 \mathrm{~kJ} / \mathrm{m}^{2}$ using essential work of fracture technique. The tested composites are considered as quasibrittle hybrid material therefore, size effect is observed to decrease nearly strength of open holes to $15 \%$ for smaller size. These observations give designer necessary knowledge and information when using these materials in applications have applied loads or frequencies amplitude. This experimental work provides a new characteristic study of fracture mechanics concept and cracking in thin copper layer based composite laminates.

\section{References}

[1] M. K. Hassan, T. Torii, and K. Shimizu, "Fatigue fracture behavior of MEMS Cu thin films."

[2] A. Wymysłowski, B. Vandevelde, and D. Andersson, "Thermal, mechanical and multi-physics simulation and experiments in micro-electronics and micro-systems," Microelectronics Reliability, vol. 47, pp. 159-160, 2007. 
[3] R. Ballarini, R. Mullen, H. Kahn, and A. Heuer, "The fracture toughness of polysilicon microdevices," MRS Online Proceedings Library Archive, vol. 518, 1998.

[4] H. D. Espinosa and B. Peng, "A new methodology to investigate fracture toughness of freestanding MEMS and advanced materials in thin film form," Journal of microelectromechanical systems, vol. 14, pp. 153-159, 2005.

[5] I. Chasiotis and W. G. Knauss, "The mechanical strength of polysilicon films: Part 1. The influence of fabrication governed surface conditions," Journal of the Mechanics and Physics of Solids, vol. 51, pp. 1533-1550, 2003.

[6] H. Kahn, N. Tayebi, R. Ballarini, R. Mullen, and A. Heuer, "Fracture toughness of polysilicon MEMS devices," Sensors and Actuators A: Physical, vol. 82, pp. 274-280, 2000.

[7] W. Sharpe, B. Yuan, and R. Edwards, "Fracture tests of polysilicon film," MRS Online Proceedings Library Archive, vol. $505,1997$.

[8] T. Tsuchiya, J. Sakata, and Y. Taga, "Tensile strength and fracture toughness of surface micromachined polycrystalline silicon thin films prepared under various conditions," MRS Online Proceedings Library Archive, vol. 505, 1997.

[9] M. Y. Abdellah, "Essential Work of Fracture Assessment for Thin Aluminium Strips Using Finite Element Analysis," Engineering Fracture Mechanics, 2017.

[10] Z. P. Bazant and J. Planas, Fracture and size effect in concrete and other quasibrittle materials vol. 16: CRC press, 1997.

[11] Z. P. Bažant, "Size effect in blunt fracture: concrete, rock, metal," Journal of Engineering Mechanics, vol. 110, pp. 518-535, 1984

[12] M. Y. Abdellah, "Delamination Modeling of Double Cantilever Beam of Unidirectional Composite Laminates," Failure analysis and prevention, 2017.

[13] M. Y. Abdellah, M. S. Alsoufi, M. K. Hassan, H. A. Ghulman, and A. F. Mohamed, "Extended finite element numerical analysis of scale effect in notched glass fiber reinforced epoxy composite," Archive of Mechanical Engineering, vol. 62, pp. 217-236, 2015.

[14] M. Y. Abdellah and M. K. Hassan, "Numerical Analysis of Open Hole Specimen Glass Fiber Reinforced Polymer," Nonlinear Engineering, vol. 3, pp. 141-147, 2014.

[15] M. Y. Abdellah, M. K. Hassan, and M. S. Alsoufi, "Fracture and Mechanical Characteristics Degradation of Glass Fiber Reinforced Petroleum epoxy Pipes," Journal for Manufacturing Science and Production, vol. 16, pp. 33-40, 2016.

[16] Y. Mohammed, M. K. Hassan, H. Abu El-Ainin, and A. Hashem, "Size Effect Analysis in Laminated Composite Structure using General Bilinear Fit," Int. J. Nonlinear Sci. Numer. Simul., vol. 14, pp. 217-224, 2013.

[17] A. Abdal-Hay, A. S. Hamdy, M. Y. Abdellah, and J. Lim, "In vitro bioactivity of implantable Ti materials coated with PVAc membrane layer," Materials Letters, vol. 126, pp. 267-270, 2014.
[18] Y. M. Mohamed K. Hassan, Abu El-Ainin H, "Improvement of Al-6061 alloys mechanical properties by controlling processing parameters," International Journal of Mechanical \& Mechatronics Engineering IJMME-IJENS, vol. 12, pp. 14-18, 2012.

[19] Y. Mohammed, M. K. Hassan, H. A. El-Ainin, and A. Hashem, "Size effect analysis of open-hole glass fiber composite laminate using two-parameter cohesive laws," Acta Mechanica, vol. 226, p. 1027,2015

[20] M. K. Hassan, Y. Mohammed, T. Salem, and A. Hashem, "Prediction of nominal strength of composite structure open hole specimen through cohesive laws," Int. J. Mech. Mech. Eng. IJMME-IJENS, vol. 12, pp. 1-9, 2012.

[21] Y. Mohammed, K. Mohamed, and A. Hashem, "Finite element computational approach of fracture toughness in composite compact-tension specimens," International Journal of Mechanical and Mechatronics Engineering, vol. 12, pp. 57-61, 2012.

[22] J. Williams and M. Rink, "The standardisation of the EWF test," Engineering fracture mechanics, vol. 74, pp. 1009-1017, 2007.

[23] S. Narasimhachary, A. Saxena, and J. Newman, "A double edge notch specimen design for tension-compression fatigue crack growth testing," Engineering Fracture Mechanics, vol. 92, pp. 126-136, 2012.

[24] S. Yilmaz, T. Yilmaz, and B. Kahraman, "Essential work of fracture analysis of short glass fiber and/or calcite reinforced ABS/PA6 composites," Polymer Engineering \& Science, vol. 54, pp. 540-550, 2014.

[25] S. Yilmaz, T. Yilmaz, and A. A. Arici, "Effect of annealing process in water on the essential work of fracture response of ultra high molecular weight polyethylene," Journal of materials science vol. 46, pp. 1758-1766, 2011.

[26] S. Hashemi, "Work of fracture of high impact polystyrene (HIPS) film under plane stress conditions," Journal of materials science, vol. 38, pp. 3055-3062, 2003.

[27] Y.-W. Mai and B. Cotterell, "On the essential work of ductile fracture in polymers," International Journal of Fracture, vol. 32, pp. 105-125, 1986.

[28] T. Kuno, Y. Yamagishi, T. Kawamura, and K. Nitta, "Deformation mechanism under essential work of fracture process in polycyclo-olefin materials," Express Polym Lett, vol. 2, pp. 404-412, 2008.

[29] F. M. Peres, J. R. Tarpani, and C. G. Schön, "An assessment of essential work of fracture testing method applied to medium density polyethylene (MDPE)," Engineering Fracture Mechanics, vol. 105, pp. 136-151, 2013.

[30] J. R. Davis, "Tensile testing, ASM International," Ohio, USA, 2004.

[31] C. H. Wang, Introduction to fracture mechanics: DSTO Aeronautical and Maritime Research Laboratory Melbourne, Australia, 1996. 